REVIEW

\title{
Contraception choice for HIV positive women
}

\author{
H S Mitchell, E Stephens
}

Sex Transm Infect 2004;80:167-173. doi: 10.1136/sti.2003.008441

UNAIDS/WHO estimates that 42 million people are living with HIV/AIDS worldwide and $50 \%$ of all adults with HIV infection are women predominantly infected via heterosexual transmission. Women with HIV infection, like other women, may wish to plan pregnancy, limit their family, or avoid pregnancy. Health professionals should enable these reproductive choices by counselling and appropriate contraception provision at the time of HIV diagnosis and during follow up. The aim of this article is to present a global overview of contraception choice for women living with HIV infection including effects on sexual transmission risk.

See end of article for authors' affiliations

.....................

Correspondence to: Dr Helen Mitchell,

Depaarment of Sexually Transmitted Diseases, Mortimer Market Centre, Off Capper Street, Camden Primary Care Trust, London WCIE 6AU, UK; hmitchell@gum.ucl.ac. uk

Accepted for publication 25 February 2004 less developed countries $70 \%$ of contraception users rely on female sterilisation and intrauterine devices in part because they are advocated by healthcare services as a result of cost effectiveness in terms of pregnancy prevention and service provision.

Contraception use and compliance is related to the range of methods available, patient choice, tions of method effectiveness, and side effects (for example, women may have less tolerance for heavy and prolonged vaginal bleeding than amenorrhoea ${ }^{56}$ ). Correct use of most user dependent methods requires a basic knowledge of reproduction and literacy skills to follow written instructions. ${ }^{7}$ In many countries women are unable to make autonomous decisions about their sexual and reproductive health because of political instability within society, lack of economic independence, and prevailing cultural or religious attitudes to women's rights. ${ }^{8}$

\section{HIV POSITIVE WOMEN AND REPRODUCTIVE HEALTH CHOICES}

Fertility is not affected by HIV infection; lower conception rates may occur as a result of behavioural change, existing subfertility, low body mass index, AIDS, and intercurrent illness particularly pulmonary tuberculosis. ${ }^{9-13}$ Female injecting opiate drug users with HIV infection also have lower fertility rates. ${ }^{14}$

In studies of women with HIV infection approximately $70 \%$ are sexually active, effective contraception use is variable, and unplanned pregnancy frequently reported..$^{15-21}$ In a cohort of Irish HIV positive women only 57\% of the sexually active women used a reliable method of contraception. ${ }^{17}$ The French SEROCO study on the impact of HIV diagnosis on sexual and contraceptive behaviour found that of the sexually active women $20 \%$ were using no contraception, $24 \%$ became pregnant, and $63 \%$ of conceptions ended in abortion. ${ }^{16}$ In the African DITRAME Project 39\% of women with HIV infection used contraceptives; factors significantly related to contraceptive use were marital status and level of education. ${ }^{19}$ The incidence of further pregnancy was 16.5 per 100 women years at risk; $50 \%$ of these pregnancies were unplanned and one third terminated by abortion, significant determinants of pregnancy were death of the previous child, cessation of breast feeding, and cessation of postpartum abstinence. ${ }^{19}$ Lactational amenorrhoea is an important and effective means of child spacing in developing countries. For HIV positive women breast feeding increases the risk of HIV transmission to her infant, which has to be balanced against the cost of artificial feeds and risk of death from gastroenteritis. prevalent health and religious beliefs, percep-
Abbreviations: COC, combined contraceptive pill; DMPA, depot medroxyprogesterone acetate; HAART, highly active antiretroviral therapy; IUDs, intrauterine devices; LNG-IUS, levonorgestrel intrauterine system; NET-EN, norethisterone enanthate; NNRTIs, nonnucleotide reverse transcriptase inhibitors; PID, pelvic inflammatory disease; Pls, protease inhibitors; POP, progestogen only pill 


\begin{tabular}{|ll|}
\hline Table 1 Contraception methods & \\
\hline Barrier & Male condom \\
& Female condom \\
Diaphragms, cervical caps, vimules \\
Oral hormonal & Combined contraceptive pill (COC) \\
& Progestogen only pill (POP) \\
Progestogen only & Depot medroxyprogesterone acetate \\
injectables & (DMPA) \\
& Norethisterone enanthate (Noristerat, \\
& NET-EN) \\
Combined injectables & Medroxyprogesterone acetate and \\
& estradiol cypionate (Cyclofem, \\
& Cycloprovera, Lunelle) \\
& Norethisterone enanthate (Mesigyna, \\
& Norigynon) \\
Combined transdermal & EVRA patch \\
implants & Implanon-1 rod etonorgestrel \\
Intrauterine devices & Jadelle-2 rods levonorgestrel \\
& Copper bearing IUDs (Cu-IUD) \\
& Levonorgestrel intrauterine system \\
& (LNG-IUS) \\
\hline & \\
\hline
\end{tabular}

The World Health Organization estimates that half a million women die annually from complications of pregnancy, childbearing, or abortion; $90 \%$ of these deaths occur in sub-Saharan Africa and Asia where there is significant unmet need for contraception provision. ${ }^{3}$ The risks of unplanned pregnancy for women with HIV infection are compounded by the risk of mother to child HIV transmission, which occurs in $30-40 \%$ of pregnancies when interventions to reduce vertical transmission, particularly antiretroviral therapy, are not available. ${ }^{22}$ In several areas of southern Africa approximately $30 \%$ of women attending antenatal clinics are infected with HIV-1. Across Africa around 1900 children acquire HIV l infection from their mother every day and three million children under 15 years are living with HIV. ${ }^{12}$ In contrast, only 720 pregnancies in HIV positive women were confirmed in the United Kingdom during 2002 and very few infants born to previously diagnosed women were infected $(<2 \%)$. $^{23}$

\section{CONTRACEPTION CHOICE AND MANAGEMENT FOR WOMEN WITH HIV INFECTION}

Women with HIV infection, like other women, may wish to plan pregnancy, limit their family, or avoid pregnancy. Health professionals should enable these reproductive choices by counselling and appropriate contraception provision at the time of HIV diagnosis and during follow up (table 2).

\section{BARRIER METHODS}

\section{Male condoms}

A high degree of protection against HIV sexual transmission is provided by consistent correct condom use ${ }^{24}$; inconsistent or incorrect use is not protective. Most global HIV transmission occurs because condoms are not used at all during sexual intercourse. ${ }^{85-27}$
Condom accidents are reported by $1-12 \%$ of users and the method contraceptive failure rate is at least $12 \% .^{27}$ Dual protection, the simultaneous use of an effective contraception method with consistent condom use, has been advocated to reduce the risk of unplanned pregnancy, horizontal transmission of HIV to a non-infected partner, transmission of resistant virus to an partner with HIV infection, and the risk of acquisition of other STIs including high risk human papillomavirus (HPV) types. ${ }^{29-31}$

\section{The female condom}

The female condom is a polyurethane sheath with two flexible rings at each end; one ring is inserted into the upper vagina and the other covers the introitus. The female condom is less likely than male condoms to leak or break during sex, but intrusion of the outer ring into the vagina is reported in $2 \%$ of coital episodes. The cumulative probability of vaginal exposure to semen with female condom use has been estimated as $3 \%$, compared to $11.6 \%$ with the male condom. ${ }^{32}$ The contraceptive failure rate is estimated at $5-21 \%$ over 12 months. ${ }^{33-35}$

\section{Diaphragm, vimules, and caps}

Diaphragms and vimules cover the cervix and parts of the vaginal wall, while caps cover only the cervix. Their use in discordant couples is not recommended, as a relatively large area of vaginal mucosa remains exposed, microtrauma during insertion, and the concomitant use of nonoxynol-9 spermicide may cause epithelial disruption and increase viral transmission risk to the male partner. ${ }^{30}$

\section{FACTORS AFFECTING CONSISTENT CONDOM USE}

In the WIHS cohort study, in which the HIV status of sexual partners is not known, $60 \%$ of women with HIV infection used condoms consistently ("always" versus "sometimes or never"). Consistent use was associated with having one partner, greater income, no illicit drug use and when condoms were the only contraceptive method used. ${ }^{15}$ Women who also use, effective or long term methods of contraception are less likely to report consistent condom use. ${ }^{15} 21303637$ Condom use is also related to whether the woman has informed her partner of her status ${ }^{19}$; less consistent use is reported by concordant couples, ${ }^{38}$ even within discordant partnerships consistent condom use is reported by only approximately $50 \%$ couples. ${ }^{39} 40$

Obstacles to greater use of male condoms include lack of availability, fear of being perceived as having multiple partners and being unfaithful to a regular partner, opposition on religious grounds, and male dominance in decision making. ${ }^{31}$ Women living with HIV infection may feel unable to disclose their HIV status and negotiate condom use with new sexual partners for fear of abandonment, domestic violence, loss of economic support, and social isolation.

The issues around female condom use are also negotiating barrier method use,,$^{42}$ method acceptability by users, ${ }^{33} 34$ and

Table 2 Factors affecting contraception choice for HIV positive women

$\begin{array}{ll}\begin{array}{l}\text { Country of residence } \\ \text { Religious, cultural, and personal beliefs }\end{array} & \begin{array}{l}\text { Access to healthcare services, methods available, and cost } \\ \text { Role of woman in society, acceptability to partner, effects on } \\ \text { menstruation }\end{array} \\ \text { HIV status of woman } & \text { CD4 count, viral load, physical wellbeing } \\ \text { HIV serostatus of partner } & \text { Concordant, discordant, not known } \\ \text { Menstrual, sexual, and reproductive history } & \begin{array}{l}\text { Menorrhagia, dysmenorrhoea, past pelvic infection, past } \\ \text { ectopic pregnancy, pregnancy planning }\end{array} \\ \text { Medical history } & \text { Abnormal liver function, past history of venous thromboembolic } \\ \text { disease, hypertension, hyperlipidaemia, current drug abuse }\end{array}$

Access to healthcare services, methods available, and cost menstruation

CD4 count, viral load, physical wellbeing ectopic pregnancy, pregnancy planning Enzyme inducers, antibiotics, teratogenic agents 
higher cost compared with the male condom. ${ }^{43}$ The WHO consultation on reuse suggested that female condoms still meet manufacturing quality assessment specifications after seven cycles of bleach disinfections, washing, drying, and relubrication. ${ }^{44}$ This protocol has not been evaluated for safety and efficacy in human use and the WHO does not recommend or promote reuse of female condoms and is currently sponsoring research to evaluate reuse protocols under local conditions.

\section{SPERMICIDES}

Nonoxynol-9 (N-9) spermicide provides no protection against sexually transmitted infections including $\mathrm{HIV}^{45}$ and frequent use increases the risk of HIV acquisition. ${ }^{46}$ A WHO Contraceptive Research and Development (CONRAD) technical consultation concluded that N-9 should not be used or promoted for the prevention of HIV in women at high risk of infection. ${ }^{47}$

There are no published studies on the female-male transmission risk with $\mathrm{N}-9$ use by women with HIV infection. It seems advisable for women with HIV infection with a discordant sexual partner to avoid N-9 spermicidals alone or with other contraceptive methods to reduce the possible risk of HIV sexual transmission. There is no evidence that condoms lubricated with N-9 are more effective in preventing pregnancy than condoms lubricated with silicone. However, where choice is limited it is better to use any condom than no condom at all. In the future, effective and acceptable microbiocides may have a role, providing HIV positive women unable to negotiate consistent condom use with a discordant partner with an additional method to reduce sexual transmission.

\section{HORMONAL CONTRACEPTION Combined oral contraception (COC)}

The combined oral contraceptive pill is an effective user dependent contraception with the non-contraceptive benefits of cycle control, reduction in menorrhagia and dysmenorrhoea. Absorption can be affected by prolonged intercurrent diarrhoea and vomiting.

The COC is metabolised by the liver and its use is contraindicated in women with abnormal liver function, ${ }^{48}$ which may be caused by alcohol abuse, acute or chronic viral hepatitis, and adverse events on antiretroviral combinations.

These factors are particularly relevant when making contraception choices for HIV positive women who are current or previous injecting drug users with chronic active hepatitis $\mathrm{C}$ infection. Current drug users often have a chaotic lifestyle that precludes effective use of user dependent contraception methods.

\section{Progestogen only pills (POP)}

Progestogen only methods may be used by women with contraindications to oestrogen use. The POP is an effective contraceptive method with correct and consistent use; ovulation is not inhibited in all users, and inconsistent use can result in pregnancy. A new progestogen only pill, Cerazette, which contains $75 \mu \mathrm{g}$ desogestrel, has recently been introduced. In studies Cerazette inhibited ovulation in $97 \%$ of cycles at 7 and 12 months after initiation; this would suggest enhanced efficacy in comparison with conventional POPs, though as yet unconfirmed by comparative trials. ${ }^{49}$

\section{Long acting progestogen only contraception Injectables}

Depot medroxyprogesterone acetate (DMPA) $150 \mathrm{mg}$ is given by deep intramuscular injection at 12 weekly intervals and norethisterone oenanthate (Noristerat) $200 \mathrm{mg}$ every 8 weeks. These methods have the advantage of not being intercourse related but require regular access to health care for repeat injections.

\section{Implants}

Implants need to be inserted by a trained health professional. Implanon is effective for 3 years, and Jadelle for 5 years (not licensed in the United Kingdom); both are highly effective, non-user dependent, and reversible methods of progestogen only contraception.

\section{Combined injectables and patches}

Combined injectables are used in some developing countries and in the United States. The weekly combined contraceptive patch (EVRA) is now licensed in some countries but availability is limited by cost. Transdermal delivery systems bypass first pass liver metabolism; this may reduce effects on clotting factors but the influence on risks of venous thrombosis and embolism is not currently known. ${ }^{50}$

\section{HORMONAL CONTRACEPTION AND HIV SEXUAL TRANSMISSION}

The vaginal epithelium as a barrier

Studies and review articles have tried to address the question of whether hormonal contraception increases the risk of HIV acquisition in women. ${ }^{32}{ }^{51-56}$ Many of these studies had methodological deficiencies owing to difficulty in overcoming confounding between sexual risk taking and choice of contraceptive method when using retrospective data. ${ }^{57} \mathrm{~A}$ large observational cohort study in Uganda recently reported that, after adjustment for behavioural confounding, hormonal contraception use was not associated with an increased risk of HIV acquisition in women. ${ }^{58}$ However, in this study more married women self selected to hormonal methods and use was based on self reporting.

There is evidence that sexual transmission risk is related to the infected individual's HIV status-for example, CD4 count, plasma HIV-1 RNA levels. Acquisition and transmission of HIV is increased in the presence of genital tract inflammation and ulceration. It is not known whether hormonal contraception use by HIV positive women, while effectively preventing unplanned pregnancy and thus vertical transmission, leads to an increased risk of transmission to sexual partners. A concern arising from macaque monkey studies is whether long acting progestogens, by inducing an anovulatory state with vaginal epithelium thinning, reduce the efficacy of the vaginal barrier. ${ }^{59}$ This barrier effect could increase the risk of HIV acquisition and sexual transmission in women. ${ }^{60}$ The presence of a cervical ectropion in association with combined hormonal contraception use has also been suggested as a risk factor for sexual HIV acquisition and transmission. $^{305661}$ Mostad et al reported that use of oral contraceptives and the 3 monthly injectable DMPA may be associated with increased shedding of HIV-1 infected cells from the cervix and vagina but they did not measure other parameters of infectivity such as free HIV-l virions or cell associated HIV-1 RNA. ${ }^{62}$

Effective HAART regimens, which result in undetectable plasma HIV-1 RNA, effectively and rapidly reduce infectivity of genital secretions and sexual transmission risk. However, there is also evidence that plasma HIV-1 RNA may not correlate directly with genital HIVI-RNA. Genital shedding was demonstrated in $25 \%$ of women with an undetectable viral load in one recent study. ${ }^{63}$ This suggests that the genital tract should be regarded as a distinct compartment with regard to viral replication, and that plasma viral loads may not predict genital viral shedding especially in the presence of genital tract inflammation and ulceration. ${ }^{63}{ }^{64}$ The additional effect of contraception methods on genital viral shedding and sexual transmission risk is uncertain. One study reported no 
association between use of hormonal contraception or intrauterine devices and increased genital shedding after adjusting for plasma RNA but did not show these data. ${ }^{64}$ The universities of California and Zimbabwe are conducting a multisite longitudinal observational study of HIV-1 genital shedding and the effect of hormonal contraception on the parameters of infectivity of women with HIV infection.

\section{Menstruation and irregular vaginal bleeding}

Irregular vaginal bleeding is common in the first 3 months of DMPA use. Over time the frequency of bleeding reduces. By 1 year approximately $50 \%$ of users will have complete amenorrhoea during at least one injection cycle, this increases to $68 \%$ by 24 months. ${ }^{65}$ Heavy or prolonged bleeding and amenorrhoea are less common in NET-EN users. Implanon induces anovulation and amenorrhoea is reported by $30-40 \%$ of users by 12 months; menstrual irregularity with frequent or prolonged bleeding can occur in about $10 \%$ of users with discontinuation rates of $11.7 \%$ by 12 months $^{66}$ The menstrual irregularities and prolonged bleeding induced by progestogen only contraceptives could increase the risk of sexual transmission during unprotected sex.

Some women, especially those with heavy or painful menstruation, may welcome amenorrhoea but there are cultural variations in acceptability and this issue should be discussed during counselling. Tricycling or continuous use of combined oral contraception, while an unlicensed use, can eliminate monthly menstruation for HIV positive women; however, this objective can also be satisfactorily achieved over time with DMPA.

\section{INTRAUTERINE DEVICES}

\section{Copper bearing intrauterine devices}

Copper bearing intrauterine devices (IUDs) are highly effective, long term (the Safe-T 380 is licensed for 8 years of use) and cost effective methods of contraception.

\section{Levonorgestrel intrauterine system}

The levonorgestrel intrauterine system (LNG-IUS) is highly effective with a failure rate of $0.1-0.2$ per 100 women years and is licensed for 5 years. The LNG-IUS has a lower rate of ectopic pregnancy (0.06 per 100 women years) and there is some evidence of a lower risk of pelvic inflammatory disease compared to copper bearing IUDs. ${ }^{67}$ The local action of LNGIUS results in endometrial thinning and irregular vaginal bleeding can occur in the first 3 months of use. By 12 months there is a $94-97 \%$ reduction in menstrual loss with amenorrhoea in $10-15 \%$ of users, which is beneficial for women with dysmenorrhoea and menorrhagia with associated iron deficiency anaemia. ${ }^{68-70}$

\section{INTRAUTERINE DEVICE USE BY WOMEN WITH HIV}

The WHO medical eligibility criteria caution against IUD and LNG-IUS use by women at risk of HIV, HIV positive women, and women with AIDS. This is a grade 3 criterion "theoretical or proved risks generally outweigh the advantages" as opposed to grade 4 which is an "unacceptable health risk." ${ }^{\prime 4}$ There are a number of concerns about IUD use by women with HIV infection relating to contraceptive efficacy, risks of sexual transmission, and acute pelvic inflammatory disease (PID). ${ }^{30}$

The theoretical risk of decreased contraceptive efficacy caused by reduced endometrial inflammatory response in advanced immunosuppression, is based on reports of IUD failures in renal transplant patients. A review of IUD failures concluded that reports of increased failure in women on steroids and anti-inflammatory drugs were not convincing and that the copper content of IUD types used was more significant. ${ }^{71}$ Sexual transmission of HIV in IUD users may be increased as a result of increased volume and duration of menses, genital inflammation, and microtrauma to the penile epithelium by the IUD threads. In a study of 98 HIV positive women in Kenya, using PCR of HIV-1 gag DNA sequences, there was no statistically significant change in cervical shedding of HIV-1 DNA at 4 months after IUD insertion. ${ }^{72}$ Within a cohort study, which included a small subgroup of male partners of HIV positive IUD users, female to male transmission was significantly increased with advanced stage of HIV infection and unprotected sex during menses and reduced by consistent condom use. ${ }^{73}$

There is a sixfold increase in risk of acute PID during the first 20 days after IUD insertion, after which PID is uncommon (1.6 per 1000 women years) except in the presence of an undiagnosed STI-for example, Chlamydia trachomatis. ${ }^{30} 7475$ A randomised trial investigating antibiotic prophylaxis at the time of IUD insertion concluded that routine prophylaxis is not warranted. ${ }^{76}$ However, this study used follow up attendance to assess IUD complication and removal rates in a population of unscreened women considered to be at low risk of sexually transmitted infection. High prevalence of HIV is known to be associated with high prevalence of other sexually transmitted infections. Routine testing, or antibiotic prophylaxis, for $C$ trachomatis is recommended before elective IUD insertion in the United Kingdom. ${ }^{77}$ These tests may not be available in developing countries. In a prospective study on $156 \mathrm{HIV}-1$ positive and 493 HIV negative unscreened women in Kenya, complication rates including pelvic inflammatory disease and removal because of pain or bleeding were similar in both groups. ${ }^{78}$

When the need for effective contraception is paramountfor example, legal abortion is unavailable, teratogenic drug therapy, and choice of available methods limited, a copper bearing IUD should be offered to HIV positive women at risk of unplanned pregnancy. Selection criteria could include monogamous relationship, negative sexually transmitted infection screen, no past history of ectopic pregnancy or PID, CD4 counts $>200$ (if available), and continuing access to medical services.

Where the LNG-IUS is available the additional noncontraceptive benefits and lower failure rate make it the preferred intrauterine method; we routinely offer this option to HIV positive women.

\section{MALE AND FEMALE STERILISATION}

Male and female sterilisation are both effective "permanent" cost effective methods of contraception. Male sterilisation has a failure rate of 1:2000 compared to $1: 200$ for female sterilisation. ${ }^{79}$ Sterilisation procedures do not reduce HIV in genital secretions nor the risk of sexual HIV transmission and it is worrying that studies show a reduction in consistent condom use in couples after one partner has undergone sterilisation. ${ }^{21} 3653$

\section{EMERGENCY CONTRACEPTION}

Emergency contraception is currently available as Levonelle-2 (Levonelle is an identical over the counter product) comprising two tablets of $750 \mu \mathrm{g}$ levonorgestrel (LNG). This is most effective when taken within the first 24 hours of unprotected sexual intercourse but can be taken up to 72 hours after unprotected sexual intercourse. A recent WHO study concluded that a single $1.5 \mathrm{mg}$ dose is as effective as the standard two dose regimen. ${ }^{80}$ The product licence has now been changed to reflect this and the new Levonelle pack has become available in the United Kingdom in 2004.

Women using condoms alone for contraception must be advised about emergency contraception. In a study of HIV positive women attending an inner London HIV outpatient 
unit, $47 \%$ of women were aware of emergency contraception, but only $37.7 \%$ had correct information about where to obtain supplies and how to use it. ${ }^{81}$

\section{DRUG INTERACTIONS AND HORMONAL CONTRACEPTION \\ Enzyme inducers}

Antiretroviral therapy

Ethinyl oestradiol and progestogens are both substrates of the cytochrome p450 CYP 3A4 system of enzymes present in the microsomal system of hepatocytes in the liver and enterocytes in the small intestine. Antiretroviral drugs that induce cytochromes-for example, ritonavir, nevirapine, increase the hepatic metabolism of hormonal contraception. Inhibitors cause decreased clearance and increased plasma concentrations of substrate drugs. When both drugs are substrates their interaction is more uncertain and may result in increased or decreased plasma concentrations. Some drugs exhibit two or all three of these properties-for example, efavirenz. ${ }^{82}$

Most of the evidence on antiretroviral drug interactions is based on pharmaceutical industry sponsored research with studies using plasma levels to give a measure of total exposure and assess interactions with oral ethinyl oestradiol and norethindrone (table 3). There is no information on antiretroviral interactions in long term contraception use, their effects on contraceptive efficacy (failure rate per 100 women years), and interactions with other hormonal methods.

Indinavir is a CYP3A4 inhibitor; the product information advises that no contraceptive dose modification is required.$^{88}$ The nucleoside analogues stavudine and didanosine are not p450 enzyme inducers, there are no data on interactions but they are not expected to interact with oral hormonal contraceptives. ${ }^{87}$

Physicians prescribing contraception can access the following useful websites for current information on antiretroviral drug interactions: www.hiv-druginteractions.org; www.hivinsite. ucsf.edu/arvdb; and www.projinf.org/fs/drugin.html.

\section{Other important enzyme inducers}

Other important CYP3A enzyme inducers which may be prescribed for women with HIV infection include rifampicin (Mycobacterium tuberculosis) and rifabutin (Mycobacterium avium intracellulare) Both drugs are highly potent inducers recognised to cause hormonal contraception failure and reduced efficacy up to 4 weeks after treatment ends. ${ }^{89}$

Other important enzyme inducing drugs include griseofulvin, toglizatone and the anticonvulsants phenobarbitone, carbamazepine, phenytoin, primidone, and topiramate. Patients who buy St John's Wort (Hypericum perforatum) over the counter to treat mild depression should be advised this is an enzyme inducer that may cause breakthrough bleeding and in theory reduced efficacy of oral hormonal contraceptives. ${ }^{90}$

\begin{tabular}{l} 
Table 3 Antiretroviral enzyme inducers that \\
may reduce efficacy of oral hormonal \\
contraceptives \\
\hline Protease inhibitors (PIs) \\
Ritonavir $^{83}$ \\
Nelfinavir \\
Lopinavir with ritonavir $^{85}$ \\
Non-nucleotide reverse transcriptase inhibitors (NNRTIs) \\
Nevirapine $e^{86}$ \\
Efavirenz $^{87}$
\end{tabular}

\section{Contraception management}

Women taking enzyme inducing drugs should be advised there is a risk of reduced efficacy of the COC and consideration given to other methods of contraception. If, after counselling, the woman wishes to continue the COC a $50 \mu \mathrm{g}$ ethinyl oestradiol dosage should be used. This can also be achieved by doubling up on lower dose pills-for example, Femodene $30 \mu \mathrm{g}$ plus one Femodette $20 \mu \mathrm{g}$ each day. There is no evidence that efficacy is further increased by tricycling (taking three consecutive packs of COC) with 4 pill free days. ${ }^{91}{ }^{92}$

There is no evidence on the interaction of enzyme inducing antiretroviral drugs with the other hormonal contraception methods. Taking the pragmatic view prescribers could apply current advice for women taking other enzyme inducing drugs.

- Women on the progestogen only pill should be advised to change to a long acting injectable progestogen or another form of contraception.

- It is common practice to reduce the injection interval for DMPA from 12 to 10 weekly but the summary of product characteristics states that no adjustment is necessary. ${ }^{92}$

\section{Overview}

- Women with HIV infection, like other women, may wish to plan pregnancy, limit their family, or avoid pregnancy. Health professionals should enable these reproductive choices by counselling and appropriate contraception provision at the time of HIV diagnosis and during follow up.

- Lactational amenorrhoea is an important and effective means of child spacing in developing countries. HIV positive women avoid breast feeding and will recommence ovulatory cycles earlier; their future contraception needs should be discussed during pregnancy or early in the postnatal period.

- Condoms have a significant user and method failure rate. Dual protection, the simultaneous use of an effective contraception method with consistent condom use, is recommended for effective prevention of unplanned pregnancy and HIV sexual transmission. Women continuing to use condoms alone must be advised how to access emergency contraception.

- Oral, injectable, and implantable hormonal contraception methods and the intrauterine system are all suitable choices for HIV positive women without medical contraindications to their use-for example, hepatitis $C$ related liver disease.

- Caution may be required in prescribing hormonal contraception for women taking enzyme inducing drugs including some HAART and anti-TB agents.

- For HIV positive women with more advanced disease, menorrhagia or irregular menstrual cycles, and current injecting drug users the Mirena (LNG-IUS) system and injectable progestogens could be recommended as they both reduce user dependency and menstrual loss.

- Male and female sterilisation should not be forgotten both are effective "permanent" cost effective methods of contraception. Women should be given the opportunity during pregnancy to consider sterilisation at the time of their elective caesarean section delivery. 
- As the main mode of action of the LNG-IUS is a direct local effect on the endometrium this may be less affected by liver enzyme induction. A pilot study in 56 women using the LNG-IUS while taking enzyme inducing drugs, predominantly anti-epileptic drugs, showed no reduction in efficacy. ${ }^{93}$

- Women using the subdermal implant may experience breakthrough bleeding and Implanon contraceptive efficacy is reduced..$^{94}$ They should be advised to change to a long acting injectable progestogen or to consistently use condoms as additional protection.

- Women using the combined hormonal patch should be advised to change to a long acting injectable progestogen or another form of contraception.

- There is little evidence on the effect of enzyme inducers on progestogen only emergency contraception; current advice is to take two tablets ( $1.5 \mathrm{mg}$ dose) followed 12 hours later by one tablet ( $750 \mu \mathrm{g}$ dose).$^{95}$ A copper IUD containing $>300 \mathrm{~mm}^{2}$ can be inserted up to 5 days after the expected date of ovulation in a regular menstrual cycle and may be used for multiple episodes of unprotected sexual intercourse and may be the preferred option for women on liver enzyme inducers after testing for sexually transmitted infection and/or routine antibiotic prophylaxis.

\section{Broad spectrum antibiotics}

Broad spectrum antibiotic use-for example, tetracyclines and penicillins, in women taking the combined oral contraceptive pill may affect gut bacteria and enterohepatic recirculation of ethinyl oestradiol. Although the failure rate is within the range associated with typical use caution is advised as some women may have significant decreases in plasma levels of ethinyl oestradiol. ${ }^{89}$ Additional consistent condom use should be advised for the duration of antibiotic treatment and for 7 days after, if the last 7 days of the pill pack are involved the next pill free interval should be omitted. This precaution is not necessary with the combined contraceptive patch, EVRA, as transdermal administration bypasses the enterohepatic cycle.

\section{Authors' affiliations}

H S Mitchell, Mortimer Market Centre, Camden Primary Care Trust, London, UK

E Stephens, Margaret Pyke Centre, Camden Primary Care Trust, London, UK

\section{REFERENCES}

1 UNAIDS/WHO. AIDS epidemic update. Geneva: UNAIDS/02.46E, December 2002.

2 International Planned Parenthood Federation. IMAP statement on hormonal methods of contraception. IPPF Medical Bulletin 2002;336: No 5 Oct.

3 United Nations Population Division Statistics Department of Economic and Social Affairs. World contraceptive use. June 2001

4 UNICEF. Statistics fertility and contraceptive use 2000

5 Bongaarts J, Westoff CF. The potential role of contraception in reducing abortion. Studies Fam Plann 2000;31:193-202.

6 Playle JF. Concepts of compliance: understandings and approaches. $\mathrm{Br} J$ Fam Plann 2000;26:213-19.

7 Gazmararian JA, Parker RM, Baker DW. Reading skills and family planning knowledge and practices in a low-income managed-care population. Obstet Gynaecol 1999;93:239-44.

8 UNAIDS. Sexual behavioural change for HIV: where have the theories taken us? Geneva: UNAIDS/99.27E, June 1999.

9 Ryder RW, Batter VL, Nsuami M, et al. Fertility rates in 238 HIV-1 seropositive women in Zaire followed for 3 years postpartum. AIDS 1991;5:1521-7.

10 Allen S, Serufilira A, Gruber V, et al. Pregnancy and contraception use among urban Rwandan women after testing and counselling. Am J Public Health 1993:83:705-10.

11 Sunderland A, Minkoff HL, Handte J, et al. The impact of human immunodeficiency virus serostatus on reproductive decisions of women. Obstet Gynecol 1992;79:1027-31.
12 Dabis F, Ekpini ER. HIV-1/AIDS and maternal and child health in Africa. Lancet 2002;359:2097-104.

13 Ross A, Morgan D, Lubega R, et al. Reduced fertility associated with HIV: the contribution of pre-existing subfertility. AIDS 1999;13:2133-41.

14 Selwyn PA, Schoenbaum EE, Davenny K, et al. Prospective study of human immunodeficiency virus and pregnancy outcome in intravenous drug users. JAMA 1989;261:1289-94.

15 Wilson T, Massad LS, Riester KA, et al. Sexual, contraceptive, and drug use behaviours of women with HIV and those at high risk for infection: results from the Women's Interagency HIV Study. AIDS 1999;13:591-8.

16 De Vincenzi I, Jadand C, Couturier E, et al. Pregnancy and contraception in a French cohort of HIV-infected women. AIDS 1997;11:333-8.

17 Murphy D, Lynch M, Desmond N, et al. Contraceptive practices in HIV seropositive females in Ireland. Int J STD AIDS 1993;4:107-9.

18 Hankins C, Tran T, Lapointe N, et al. Sexual behaviour and pregnancy outcome in HIV-infected women. J AIDS Hum Rep 1998;18:479-87.

19 Desgrées-du-Loû A, Msellati P, Viho I, et al. Contraceptive use, protected sexual intercourse and incidence of pregnancies among African HIV-infected women. DITRAME ANRS 049 Project, Abidjan 1995-2000. Int J STD AIDS 2002; 13:462-8.

20 Hankins $\mathrm{C}$, Tran T, Lapointe N, et al. Sexual behaviour and pregnancy outcome in HIV-infected women. J AIDS Hum Rep 1998;18:479-87.

21 Magalhaes J, Amaral E, Giraldo PC, et al. HIV Infection in women: impact on contraception. Contraception 2002;66:87-91.

22 BHIVA. Guidelines for the management of HIV infection in pregnant women and the prevention of mother-to-child transmission. London: Br HIV Assoc (BHIVA) 2001 (www. bhiva.org).

23 RCOG. National study of HIV in pregnancy. Newsletter 55, July 2003.

24 Davis K, Weller S. The effectiveness of condoms in reducing heterosexual transmission of HIV. Family Planning Perspectives 1999;31:272-9.

25 Steiner MJ, Cates W Jr. The real problem with male condoms is non-use. Sex Transm Dis 1999;26:459-62.

26 Marks G, Burris S, Petersen TA. Reducing sexual transmission of HIV from those who know they are infected: the need for personal and collective responsibility. AIDS 1999;13:297-306.

27 Cates W, Stone KM. Family planning, sexually transmitted diseases and contraceptive choice: a literature update-Part I. Fam Plann Perspect 1992;24:75-84.

28 Trussel J, Warner DL, Hatcher RA. Condom slippage and breakage rates. Family Planning Perspectives 1992;24:20-3.

29 International Planned Parenthood Federation (IPPF). International Medical Advisory Panel (IMAP) statement on dual protection against unwanted pregnancy and sexually transmitted infections, including HIV. IPPF Medical Bulletin 2000;34: No 4 Aug.

30 Carlin EM, Boag FC. Women, contraception and STDs including HIV. Int J STD AIDS 1995;6:373-86.

31 UNDP/UNFPA/WHO/World Bank Special Programme of Research, Development and Research Training in Human Reproduction, Department of Reproductive Health and Research, WHO. HIV/AIDS makes dual protection a must. Progress in Reproductive Health Research Quarterly Newsletter 2002; No 59.

32 Daly CC, Helling-Giese GE, Mati JK, et al. Contraceptive methods and the transmission of HIV: implications for family planning. Genitourin Med 1994;70:110-17.

33 Bounds W, et al. A Female condom (Femshield): a study of its useracceptability. Br J Fam Plann 1988;14:83-7.

34 Farr G, et al. Contraceptive efficacy and acceptability of the female condom. Am J Pub Health 1994;84:1960-4.

35 Trussell J. Contraceptive efficacy of the Reality female condom. Contraception 1998;58:147-8.

36 Diaz T, Scable B, Chu S. Relationship between use of condoms and other forms of contraception among HIV-infected women. Obstet Gynaecol 1995:86:277-82.

37 Frank ML, Bateman L, Poindexter AN. Planned condom use by women with Norplant implants. Adv Contracept 1993;9:227-32.

38 Clark RA, Kissinger P, Bedimo A, et al. Determination of factors associated with condom use among women infected with human immunodeficiency virus. Int J STD AIDS 1997;8:229-33.

39 Allen S, Meinzen-Derr J, Kautzman M, et al. Sexual behaviour of HIV discordant couples after HIV counselling and testing. AIDS 2003;17:733-40.

40 de Vincenzi I, et al. A longitudinal study of human immunodeficiency virus transmission by heterosexual partners N Engl J Med 1994;331:341-6.

41 Feldblum, Welsh MJ, Steiner MJ. Don't overlook condoms for HIV prevention. Sex Transm Infect 2003;79:268-9.

42 Kalichman SC, Rompa D, Cage M. Factors associated with female condom use among HIV-seropositive women. Int J STD AIDS 2000;1 1:798-803.

43 International Planned Parenthood Federation. IPPF Medical Bulletin 2001;35: No 1 Feb.

44 WHO. Information update: considerations regarding the reuse of the female condom, July 2002 (www.who.int/reproductive-health/rtis/reuse.en.html).

45 Wilkinson D, Tholandi M, Ramjee G, et al. Nonoxynol-9 spermicide for prevention of vaginally acquired HIV and other sexually transmitted infections: systematic review and meta-analysis of randomised controlled trials including more than 5000 women. Lancet Infect Dis 2002;2:613-17.

46 Van Damme L, Ramjee G, Alary M, et al. Effectiveness of COL-1492, a nonoxynol-9 vaginal gel, on HIV-1 transmission in female sex workers: a randomised controlled trial. Lancet 2002;360:971-7.

47 WHO/CONRAD Technical Consultation on Nonoxynol-9. Geneva: WHO, October 2001, Summary Report. 
48 WHO. Medical eligibility criteria for contraceptive use, 2nd ed. Available for download on the internet at www.who.int/reproductive-health/publications/ RHR_00_2_medical eligibility_cr.

49 New Product Review. Desogestrel-only pill (Cerazette). Clinical Effectiveness Unit. Aberdeen: Faculty of Family Planning and Reproductive Health Care, April 2003

50 EVRA (norelgestromin/ethinyl oestradiol transdermal system) product information. Janssen-Cilag International NV, Belgium. April 2003.

51 Martin HL Jr, Nyange PM, Richardson BA, et al. Hormonal contraception, sexually transmitted diseases and risk of heterosexual transmission of human immunodeficiency virus type 1. J Infect Dis 1998;178:1053-9.

52 Clark RA, Kissinger P, Williams T. Contraceptive and sexually transmitted diseases protection among adult and adolescent women infected with human immunodeficiency virus. Int J STD AIDS 1996;7:439-42.

53 Cates W, Stone KM. Family Planning, sexually transmitted diseases and contraceptive choice: a literature update-Part II. Fam Plann Perspect 1992; 24:122-8.

54 Sinei SKA, Fortney JA, Kigondu CS, et al. Contraceptive use and HIV infection in Kenyan family planning clinic attenders. Int J STD AIDS 1996;7:65-70.

55 Mati JKG, Hunter DJ, Maggwa BM, et al. Contraceptive use and the risk of HIV infection in Nairobi, Kenya. Int J Gynecol Obstet 1995;48:61-7.

56 Howe JE, Minkoff HL, Duerr AC. Contraceptives and HIV. AIDS 1994;8:861-71.

57 Stephenson JM. Systematic review of hormonal contraception and risk of HIV transmission: when to resist meta-analysis. AIDS 1998;12:545-53.

58 Kiddugavu M, Makumbi F, Wawer MJ, et al. Hormonal contraceptive use and HIV-1 infection in a population-based cohort in Rakai, Uganda. AIDS 2003; 17:233-40.

59 Marx PA, Spira Al, Gettie A, et al. Progesterone implants enhance SIV vaginal transmission and early virus load. Nat Med 1996;2:1084-9.

60 Kraehenbuhl J-P, Wain-Hobson S. Breaching barriers. Nat Med 1996;2:1080-2.

61 Moss GB, Clemetson D, D'Costa L, et al. Association of cervical ectopy with heterosexual transmission of human immunodeficiency virus: results of a study of couples in Nairobi, Kenya. J Infect Dis 1991;164:588-91.

62 Mostad SB, Overbaugh J, DeVange DM, et al. Hormonal contraception, vitamin A deficiency, and other risk factors for shedding of HIV-1 infected cells from the cervix and vagina. Lancet 1998;350:922-7.

63 Fiore JR, Suligoi B, Saracino A, et al. Correlates of HIV-1 shedding in cervicovaginal secretions and effects of antiretroviral therapies. AIDS 2003; 17:2169-76.

64 Kovacs A, Wasserman SS, Burns D, et al. Determinants of HIV-1 shedding in the genital tract of women. Lancet 2001;358(9293):1593-601.

65 Bigrigg A, Evans M, Gbolade B, et al. Depo Provera. Position paper on clinical use, effectiveness and side effects. Review article. Br J Fam Plann 1999;25:69-76 and erratum 1999;26:52-3.

66 Edwards JE, Moore A. Implanon: a review of clinical studies. Br J Fam Plann 1999;24:S3-16.

67 Andersson K, Odlind V, Rybo G. Levonorgestrel-releasing and copperreleasing IUDs during five years of use: a randomised comparative trial. Contraception 1994:49:56-72.

68 Andersson JK, Rybo G. Levonorgestrel-releasing intrauterine device in the treatment of menorrhagia. Br J Obstet Gynaecol 1990;97:690-4.

69 Duckitt K, Shaw RW. Is medical management of menorrhagia obsolete? Br J Obstet Gynaecol 1998;108:569-72.

70 Sturridge F, Guillebaud J. Gynaecological aspects of the levonorgestrelreleasing intrauterine system Br J Obstet Gynaecol 1997; 104:285-9.

71 Thonneau P, Goulard H, Goyaux N. Risk factors for intrauterine device failure: a review. Contraception 2001;64:33-7.
72 Richardson B, Morrison CS, Sekadde-Kigondu C, et al. Effect of intrauterine device use on cervical shedding of HIV-1 DNA. AIDS 1999;13:2091-7.

73 European Study Group on Heterosexual transmission of HIV. Comparison of female to male and male to female transmission of HIV in 536 stable couples. BMJ 1992;304:809-13.

74 Farley TM, Rosenburg MJ, Rowe PJ, et al. Intrauterine devices and pelvic inflammatory disease: an international perspective. Lancet 1992;339:1005-8.

75 Hubacher D, Lara-Ricalde R, Taylor DJ, et al. Use of Copper Intruterine Devices and the Risk of Tubal Infertility among Nulligravid Women. N Engl J Med 2001;345:561-7.

76 Walsh T, Grimes D, Frezieres R, et al. Randomised controlled trial of prophylactic antibiotics before insertion of intrauterine devices. Lancet 1998;351:1005-9.

7731 st Study Group. Recommendations arising from the 31 st Study Group: the prevention of pelvic infection. J Br Fertil Soc 1997;2:16-17.

78 Sinei SK, Morrison CS, Sekadde-Kigondu C, et al. Complications of use of intrauterine devices among HIV-1 infected women. Lancet 1998:351:1238-41.

79 RCOG. National evidence-based clinical guidelines. Sterilisation-male and female www.rcog.org.uk.

80 Von Hertzen H, Piaggio G, Ding J, et al. Low dose Mifepristone and two regimens of levonorgestrel for emergency contraception: a WHO mulitcentre randomised trial. Lancet 2002;360:1803-10.

81 Olaitan A, Madge S, Reid W, et al. Contraceptive use, and knowledge of postcoital contraception amongst HIV-infected women: a comparison with an HIV negative population. Br J Fam Plann 1996;22:127.

82 Piscitelli SC, Gallicano KD. Interactions among drugs for HIV and opportunistic infections. N Engl J Med 2001;344:984-96.

83 Ouellett D, Hsu A, Qian J, et al. Effect of ritonavir on the pharmokinetics of ethinyl oestradiol in healthy female volunteers. Br J Pharmacol 1998;46:111-16.

84 Hoffmann-La Roche Ltd, Basle, Switzerland/Agouron Pharmaceutical Inc, La Jolla, USA. Data on file: Viracept (nelfinavir mesylate), Study AG. 1343-526.

85 Kaletra Product Information, Abbott Laboratories, 2000

86 Mildvan D, Yarrish R, Hutman H, et al. Viramune (nevirapine) and OrthoNovum 1/35 (ethinyl oestradiol/norethindrone) Interaction Study in HIV-1 infected Women. Abstract \#89 Boehringer Ingelhin Pharmaceuticals, Inc, Ridgefield, CT, USA..

87 Sue N. Senior Medical Information Pharmacist, Bristol-Myers Squibb Pharmaceuticals Ltd. Medical Information Dept. Personal communication, Feb, 2003.

88 Indinivar (Crixivan) Product Information, Merck Sharp 1999.

89 Dickinson BD, Altman RD, Nielsen N, et al. Drug interactions between oral contraceptives and antibiotics. Obstet Gynecol 2001;98:853-60

90 Breckenridge A. Important interactions between St John's Wort (Hypericum perforatum) preparations and prescribed medicines. London: Committee on Safety of Medicines, 29 Feb 2000

91 De Souza A, Brechin S, Penney G, from the Clinical Effectiveness Unit (CEU) The members' enquiry service: frequently asked questions. Br J Fam Plann 2003;29:225-6.

92 Elliman A. Interactions with hormonal contraception. FACT review article. Br J Fam Plann 2000;26:109-11.

93 Bounds W, Guillebaud J. Observational series on women using the contraceptive Mirena concurrently with anti-epileptic and other enzymeinducing drugs. Br J Fam Plann 2002;28:78-80.

94 Implanon Product Information 2002 Organon Laboratories Ltd.

95 Faculty of Family Planning and Reproductive Health Care Clinical Effectiveness Unit. FFPRHC Guidance. Emergency Contraception (April 2003). 